\title{
A voz do Sul na CONFINTEA VI: a agenda da África
}

\author{
John Aitchison \\ Universidade KwaZulu de Natal, África do Sul
}

Tradução: Dagmar Zibas

\section{Introdução}

Na África, a Conferência Preparatória para a Conferência Internacional de Educação de Adultos (CONFINTEA) VI, pautada pelo tema "O poder da aprendizagem de jovens e adultos para o desenvolvimento africano", foi realizada em Nairóbi, no Quênia, no início de novembro de 2008. Ao final das deliberações, em uma significativa declaração, representantes de 46 países afirmaram seu compromisso de transformar a educação e a aprendizagem de jovens e adultos em um direito e em realidade para os povos da África, no contexto da luta pelo desenvolvimento sustentável e pela cultura da paz.

Tanto o relatório regional quanto a Declaração da Conferência ${ }^{1}$ levantaram questões sobre as formas

${ }^{1}$ Em 2007, como processo de preparação para a VI CONFINTEA, todos os Estados-membros da Organização das Nações Unidas para a Educação, a Ciência e a Cultura (UNESCO) foram chamados a preparar relatórios nacionais sobre a situação da aprendizagem e educação de adultos e sobre os seus principais avanços desde 1997 (data da V CONFINTEA). Esses relatórios nacionais são acessáveis como a educação e a aprendizagem de adultos ao longo da vida serão consideradas e definidas na CONFINTEA VI, a ser realizada em Belém do Pará, Brasil, em dezembro de 2009. Sendo um relatório específico do Sul, o documento africano pode ser comparado a outro relatório também específico do Sul, aquele referente a América Latina e Caribe, mas pode também ser cotejado com o documento do Norte, proveniente da Europa e da América do Norte.

no portal do Instituto de Aprendizagem ao Longo da Vida (Institute of Lifelong Learning), da UNESCO http://www.unesco.org/uil/ en/nesico/confintea/confinteacountries.htm. Foram encomendados relatórios regionais para sintetizar os relatórios nacionais. Nessas sínteses, foram também usadas, quando necessário, outras fontes, como diferentes relatórios e documentos de pesquisa. Os relatórios regionais e as declarações das conferências preparatórias estão disponíveis em http://www.unesco.org/en/confinteavi/download/. Outro importante documento é o relatório da sociedade civil, elaborado pela Plataforma Africana para Educação de Adultos e apresentado em Nairóbi com o título: Construindo parcerias para uma visão renovada da Educação de Adultos na África, disponível em http:// www.africacsplateforme.org/Portuguese/docspor.html. 


\section{O contexto da África subsaariana}

O contexto subsaariano é, sem dúvida, do Sul: três quartos das pessoas mais pobres do mundo vivem na África subsaariana; entre 1990 e 2004, o número desses muito pobres cresceu cerca de $200 \%$ na região e, no mesmo período, a participação do continente na pobreza global aumentou de $19 \%$ para $31 \%$. Em qualquer indicador importante de pobreza, a África está em desvantagem. É também um continente desafiado pelo rápido aumento da população e pela necessidade de suprir as carências educacionais e de subsistência dos jovens. Além da pobreza, os Estados africanos ainda enfrentam dificuldades de atuar em situações multiétnicas e multilinguísticas, compostas por grandes contingentes da população inseridos em economias rurais e de subsistência.

A África subsaariana, depois da descolonização (nas décadas de 1950 e 1960) e durante o período da Guerra Fria, foi maltratada por regimes de partido único e por ditaduras. Nas décadas de 1980 e 1990, a instalação de democracias multipartidárias trouxe problemas específicos, não sendo o menor aquele que diz respeito aos processos de transição, quando partidos de oposição ganham eleições, mas os perdedores, com ameaças de violência, insistem em um acordo para dividir o poder (como aconteceu recentemente no Quênia e no Zimbábue). A República Democrática do Congo vivenciou uma trágica guerra civil que causou mais mortes do que qualquer outro conflito no século XXI.

A reconstrução política do continente está agora nas mãos da União Africana (substituta da corrupta e extinta Organização da Unidade Africana), com programas ambiciosos, mas notavelmente carentes de financiamento, como a Nova Parceria para o Desenvolvimento da África (New Partnership for Africa's Development - NEPAD). Compreensivelmente, o avanço da democratização - principalmente, de uma democratização que realmente se estenda além das estreitas elites pós-coloniais - requer uma vibrante sociedade civil. Sem dúvida, movimentos da sociedade civil estão cada vez mais fortes e mais bem organizados, tanto no âmbito regional quanto no continental. Isso tem claras implicações para a educação de adultos, existindo agora uma Plataforma Africana para a Educação de Adultos. ${ }^{2}$ Infelizmente, a democratização é construída sobre uma base econômica frágil, pois a África está apenas começando a se recuperar de décadas de má governança e corrupção (além de conflitos internacionais, guerras civis e golpes de Estado). Apesar de ganhos modestos em prosperidade na última década (ganhos agora ameaçados pela crise financeira mundial iniciada no final de 2008), a pobreza continua endêmica no continente, tornando-se pior em razão da catastrófica praga da AIDS, que ataca de modo devastador os contingentes economicamente mais ativos.

O relatório regional Pré-CONFINTEA VI teve, pois, que ser elaborado dentro de um contexto de esforços para mudar essa situação - uma agenda claramente congruente com os Objetivos de Desenvolvimento do Milênio (Millennium Development Goals - MDGs) ${ }^{3}$ e, no que diz respeito especificamente à educação, congruente com os objetivos do Educação para Todos (Education for All - EFA). ${ }^{4}$ O papel da aprendizagem e educação de adultos (Adult Learning and Education - ALE) $)^{5}$ está, implícita ou explicitamente, inserido

${ }^{2}$ A plataforma é uma aliança de quatro redes africanas da sociedade civil: Campanha Rede África de Educação para Todos (Africa Network Campaign on Education for All - ANCEFA), Rede de Comunicação e Desenvolvimento das Mulheres Africanas (African Women's Development and Communication Network FEMNET), Associação Pan-Africana para Alfabetização e Educação de Adultos (Pan African Association for Literacy and Adult Education - PAALAE) e a Rede Africana Refletir (African Reflect Network - PAMOJA).

${ }^{3} \mathrm{O}$ documento completo está em: http://www.un.org/millenniumgoals/.

${ }^{4} \mathrm{O}$ texto com os objetivos está em: http://www.unesco.org/ education/efa/.

${ }^{5}$ A nova denominação e o acrônimo resultante, construídos para a VI CONFINTEA, presumivelmente tentam diferenciar a “aprendizagem de adultos” da "aprendizagem ao longo da vida" (do berço ao túmulo), chamando a atenção para a aprendizagem 
nessas iniciativas. Isso provoca novos e contínuos desafios para a área quando se examina o que foi feito desde a V CONFINTEA, realizada em 1997.

Tomando-se a alfabetização como chave para o desenvolvimento educacional, o quadro inicial é desencorajador. Depois de décadas de esforços sustentáveis para erradicar o analfabetismo na África, as taxas referentes a adultos analfabetos (pessoas de 15 anos e mais) continuam altas, registrando disparidades entre homens e mulheres e entre áreas urbanas e rurais. As consequências disso são severas: baixa produtividade e baixos níveis de renda; há ainda certa relação entre tais consequências do analfabetismo e o avanço do HIV/AIDS, o que por sua vez afeta os esforços para o desenvolvimento nacional. Um registro positivo é o enorme crescimento da educação primária universal gratuita, que aliviará, gradualmente, esse problema, embora as taxas de desistência continuem altas, o que aumenta o número de adultos que necessitam de educação básica. Em contrapartida, as exigências de financiamento da educação primária podem desviar recursos do subsetor de educação de adultos, o qual permanece relativamente marginal e carente de financiamento.

A marginalização da educação de adultos é compreensível: em tempos de escassez, ela não é percebida como prioridade. A capacidade de renovação da educação de adultos (em universidades e outras instituições) pode ter declinado desde a V CONFINTEA, em 1997. Além disso, a contínua identificação da educação de adultos apenas com a alfabetização e com a educação básica reforça sua marginalização, colocando-a em desvantagem quanto ao acesso a recursos doados, na medida em que as prioridades e "modas" de financiamento dos doadores internacionais mudem.

Assim, a partir dos relatórios dos Estadosmembros para a CONFINTEA VI, ficou evidente que na África os desafios enfrentados pela aprendizagem e educação de adultos são sistêmicos, maciços e de grande amplitude. Esses desafios são agravados pelas

informal, bem como para aquela aprendizagem facilitada pelas atividades da educação formal e da não-formal. sombrias perspectivas econômicas atuais. Para que a CONFINTEA VI seja um veículo para enriquecer o perfil da aprendizagem e educação de adultos e para terminar com sua marginalização, serão necessários o comprometimento e a energia de todos os países da região.

\section{As principais questões}

Quais foram, então, as principais questões identificadas na África subsaariana? Ficaram evidentes questões muito básicas, que não estão diretamente afetas à educação: desenvolvimento sustentável, estabelecimento de uma cultura de paz, atendimento das necessidades da juventude e alívio da pobreza. Presumivelmente, a educação de adultos deve ser instrumental para o encaminhamento desses temas. Entre as questões levantadas, a única claramente relacionada à educação de adultos diz respeito ao direito geral das pessoas a ela.

Quando se compara a identificação das principais questões africanas com aquelas expressas pelo Norte em sua declaração equivalente resultante da reunião preparatória para a CONFINTEA VI, ${ }^{6}$ fica óbvio que as necessidades básicas - sociais e econômicas - são prioritárias no Sul, enquanto no Norte o principal foco está na função específica da educação de adultos, embora seja reconhecido seu papel na capacitação das pessoas para agir mais efetivamente e participar mais ativamente das questões sociais, culturais e econômicas que confrontam a sociedade. É ainda no Norte que se pode discutir o equilíbrio entre o aspecto vocacional e o não vocacional da educação de adultos para o enriquecimento da vida.

Evidentemente os contextos do Sul e do Norte são diferentes, embora na reunião de Nairóbi, em vista da

${ }^{6}$ A Declaração pan-europeia sobre aprendizagem de adultos para a equidade e inclusão no contexto de mobilidade e da competitividade foi elaborada na conferência preparatória para a VI CONFINTEA, em Budapeste, de 3 a 5 de dezembro de 2008. Disponível em: http://www.unesco.org/uil/en/nesico/confintea/ confinteacountries.htm. 
crescente certeza da extensão global da crise financeira, tenha sido considerado que todas as regiões seriam afetadas por ela e que em todo o mundo aumentariam muito as críticas às atuais políticas econômicas e aos sistemas de regulação (ou à falta deles). A África é um mundo jovem, com populações e urbanização em expansão e baixos níveis de educação. Em contraste, o Norte possui populações em processo de envelhecimento e, em muitos casos, em declínio, com uma força de trabalho que crescentemente alcança o terceiro grau de escolarização (para empregos que cada vez mais requerem níveis mais altos de qualificação) e com crescente participação na educação de adultos. No Norte, a mobilidade das pessoas entre países é efetiva (como bem exemplificado pela União Europeia) e há uma impressionante gama de mecanismos que facilitam a harmonização das qualificações e dos padrões educacionais entre as regiões. A África criou a nova União Africana e tem vários tratados assinados, mas está ainda engatinhando em termos de harmonização e cooperação. Além disso, a valorização das perspectivas africanas (filosofias, culturas, idiomas) ainda é, em grande parte, retórica.

\section{Estruturas: políticas, legislação, governança}

Poucos países na África têm políticas específicas e regulamentadas para a educação de adultos (as exceções são: Benin, Burkina Faso, Chade, Cabo Verde, Eritreia, Guiné, Madagascar, Namíbia e África do Sul), embora diversos tenham elaborado documentos de política, os quais, todavia, muitas vezes não são regulamentados durante anos a fio. Alguns poucos países também mencionam, em suas constituições, o direito de todos à educação. São mais comuns as referências breves e esparsas à alfabetização ou à educação básica (educação não-formal) em políticas e planos estratégicos para educação geral, para o desenvolvimento mais amplo ou para a diminuição da pobreza. Assim, políticas adequadas para a educação de adultos continuam marginais, embora consideradas fator importante para o desenvolvimento.

A ausência de legislação reflete a fragilidade das políticas para a aprendizagem e educação de adultos.
Poucos países têm qualquer legislação para essa área e, quando têm, ela tende a focalizar, de forma estreita, apenas a alfabetização e a educação básica. ${ }^{7}$ Esse quadro é radicalmente diferente daquele que prevalece na União Europeia e nos países da Organização para a Cooperação e Desenvolvimento Econômico (OCDE), onde há estruturas sólidas de política nacional e regional para aprendizagem ao longo da vida e educação de adultos.

Uma das características da situação subsaariana é que, nos países onde existem políticas específicas de educação de adultos, elas tendem a englobar um largo espectro de questões de aprendizagem ao longo da vida e de desenvolvimento, enquanto nos países onde as políticas são fracas ou inexistentes, qualquer foco por parte do Estado concentra na alfabetização e na educação básica de adultos/educação não-formal.

Embora a necessidade de articulação entre a educação formal e a não-formal seja frequentemente mencionada nos relatórios nacionais, as políticas tendem a ser tímidas ou omissas sobre a forma como tal articulação pode ser alcançada. Muitos relatórios expressaram esperança de que políticas para o estabelecimento de estruturas de qualificações nacionais possam servir para criar o vínculo necessário.

A gestão da educação de adultos tende a estar alocada nos ministérios de educação ou em ministérios que lidam com questões de gênero ou de desenvolvimento. Dentro dos ministérios, as divisões ou departamentos de educação são elementos menores ou marginais e, usualmente, focalizam apenas a alfabetização e educação básica de adultos ou educação não formal. Em diversos casos, a responsabilidade pela educação de adultos está dividida entre dois ou mais ministérios, o que dificulta a coordenação. Raramente, a educação de adultos é administrada por uma agência

7 “Educação básica de adultos" é a denominação mais apropriada para a educação que, na maior parte da África, é, invariável e erroneamente, chamada de educação não-formal, que na prática é uma equivalente altamente formal (e crescentemente formal quanto à certificação), mas sem os recursos da educação elementar oferecida para crianças. 
semiautônoma (e, quando isso acontece, parece haver maiores benefícios).

A última década foi caracterizada por enormes pressões políticas para descentralização governamental. Entretanto, parece que isso teve pouco impacto positivo sobre a educação de adultos, principalmente porque a descentralização da tomada de decisões não foi acompanhada de recursos, notadamente financeiros, resultando em outorgas de responsabilidades, mas sem financiamento. O modelo faire-faire (fazer-fazer) ${ }^{8}$ - caracterizado pela terceirização ou pela contratação por meio de parecerias público-privadas ou com organizações não-governamentais -, implementado em diversos países francófonos da África Ocidental, tem tido alguns resultados positivos, mas também negativos, o que em alguns casos tornou a educação de adultos ainda menos visível.

Na Conferência de Nairóbi, houve um acordo quanto à necessidade de que cada país tenha uma política abrangente, nacional, para a aprendizagem e educação de jovens e adultos, bem como planos de ação que também possibilitem uma política inclusiva de língua e de apoio para a construção de ambientes letrados. Essas políticas devem ser sustentadas por legislação junto com a capacidade fortalecida para torná-las efetivas. Devem, ainda, considerar estratégias para a diminuição da pobreza.

\section{Parcerias}

A Declaração de Nairóbi argumentou que o governo e a sociedade civil devem trabalhar juntos para concretizar estratégias para melhorar sua colaboração

${ }^{8}$ N.T.: o modelo faire-faire é definido pela Associação para o Desenvolvimento da Educação na África (Association for the Development of Education in Africa), em documento editado em reunião em Liberville, Gabão, em março de 2006, da seguinte forma: “A estratégia faire-faire é um tipo de descentralização. Especificamente, significa delegar a atores sociais reconhecidamente capazes a concepção e implementação, dentro da estrutura estabelecida pelo Estado, de programas destinados a atender necessidades educacionais básicas". em atividades de aprendizagem de adultos. Embora parcerias com múltiplos atores sociais certamente existam e tenham sido apoiadas por agências técnicas e de desenvolvimento e por organizações internacionais, é também evidente que, na educação de adultos, o trabalho de segmentos sociais e de instituições da sociedade civil (organizações não-governamentais, organizações sociais, religiosas e de outros tipos) não é devidamente reconhecido, precisando ser ativamente encorajado e apoiado. Para o desenvolvimento das parcerias, devem ser criadas estruturas mais transparentes e passíveis de fiscalização - esse foi um aspecto fortemente enfatizado no relatório da Plataforma Africana para Educação de Adultos, intitulado Construindo parcerias para uma visão renovada da educação de adultos na África.

\section{Estruturas de financiamento}

Previsivelmente, os governos são os maiores financiadores dos programas de educação de adultos implementados pelos principais ministérios envolvidos (embora, em muitos casos, o financiamento e o uso das instalações estatais possam ser subvencionados por doações ou por apoio bilateral). Organizações não-governamentais e organizações religiosas prestam assistência principalmente a novos projetos; as últimas também cedem suas instalações (embora as organizações não-governamentais enfrentem uma situação difícil na medida em que, crescentemente, têm que conseguir recursos por meio de contratos com governos, os quais podem tender a redirecionar os financiamentos para favorecer grupos diferentes daqueles originalmente escolhidos). Para o treinamento de habilidades, é vital o financiamento proveniente do setor privado, direto ou através do imposto instituído para o desenvolvimento de competências. ${ }^{9}$ A área é muito consciente do fato de que o financiamento para a educação de adultos é marginal e não priorizado.

${ }^{9}$ N.T.: Alguns países da África e da Ásia instituíram uma legislação que estabelece um imposto a ser pago por empresas para financiar treinamento profissional de jovens. Em inglês, essa legislação é conhecida como Skills Levies Acts. 
Recursos do governo e da comunidade de doadores são muitas vezes erráticos, episódicos, restritos e raramente destinados a desenvolvimento de longo prazo, mesmo quando têm por foco o desenvolvimento institucional. Pouquíssimos países aproximam-se da meta de destinar - para a alfabetização e para a educação de adultos - pelo menos $3 \%$ do orçamento nacional da educação. (Toda a questão de pontos de referência - benchmarks - para políticas e "metas de financiamento" está engatinhando, embora seja muito discutida e frequentemente mal compreendida.) O que o Norte vem fazendo, e de forma bastante proativa, é investir de maneira programada na educação de adultos, o que pode evitar que, mais tarde, os custos sociais sejam mais altos.

\section{Organização, coordenação e implementação}

A maior parte dos países africanos possui uma unidade ou um departamento nacional que é responsável por organizar e implementar a educação de adultos, focalizando usualmente a alfabetização, a educação básica e, às vezes, também a educação secundária. Em geral, essas unidades são denominadas “departamentos de educação não-formal”, embora, na realidade, administrem escolarização alternativa ou supletiva, mas bastante formal, para crianças, jovens e alguns adultos. Há raros conselhos ou comitês representativos para assistir as funções de coordenação e supervisão, e existe pouca evidência de coordenação interministerial, bem como poucas estruturas de planejamento, implementação e governança multissetorial.

As organizações não-governamentais desempenham papel importante e inovador na maioria dos países, mas sua escala de operação é geralmente pequena. Alguns países têm associações de educação de adultos e/ou associações de educandos adultos, porém seu impacto é de difícil avaliação. Embora frequentemente as organizações da sociedade civil sejam parceiras-chave dos governos, sua contribuição não é oficialmente reconhecida de forma plena.

Os principais focos dos programas tendem a ser bastante previsíveis e convencionais: analfabetos, jo- vens fora da escola, mulheres, campo etc. Os principais programas estabelecidos, pelo menos como constam dos relatórios, são: alfabetização e educação básica. Um dos avanços, desde a V CONFINTEA, diz respeito à sensibilização para os temas de gênero, pois as mulheres parecem ter agora maior facilidade de acesso à educação de adultos, sendo mais altas suas taxas de participação.

Lamentavelmente, os dados sobre tendências e taxas de participação desde 1997 são relativamente raros e frágeis e, quando disponíveis, referem-se principalmente à alfabetização, à educação básica e à assim chamada educação não-formal. Há necessidade clara de alguma padronização dos dados informados sobre provisão ou cobertura.

\section{Provisão de alfabetização e de educação básica de adultos}

A alfabetização é uma das formas mais comuns e necessárias de provisão, mas deve ser registrado que os esforços dos últimos doze anos falharam no atendimento ao crescente número de adultos que não podem ler ou escrever.

Os programas de alfabetização tomam diferentes formas: campanhas (que pareciam estar em declínio até que, em 2008, a África do Sul implementou uma); a chamada alfabetização funcional (significando, frequentemente, educação básica ou alfabetização articuladas ao ensino de algumas habilidades técnicas e para a vida ou vinculadas a treinamento para a geração de renda); programas participativos e inovadores desenvolvidos por organizações não-governamentais (tais como o método Reflect ${ }^{10}$ ); e o mais recente interesse: os projetos de alfabetização familiar e intergeracional.

Infelizmente, a alfabetização e a educação básica de adultos caracterizam-se por um quadro de pessoal subqualificado e mal treinado, que recebe os mais

${ }^{10}$ N.T.: Reflect method refere-se a estratégias de fortalecimento das comunidades para mudanças de comportamentos e atitudes (empower community techniques) implementadas por organizações não-governamentais na África, principalmente com a finalidade de combate à AIDS. 
baixos salários. Tal quadro é formado crescentemente por instrutores com contratos temporários e de tempo parcial. Um aspecto positivo a destacar é que cada vez mais pelo menos o processo inicial de alfabetização tende a ser desenvolvido nas línguas locais, havendo algumas tentativas inovadoras de fornecer materiais didáticos e de leitura em nível de pós-alfabetização, além de apoio de biblioteca, na língua materna.

É difícil saber quais são os efeitos de todos esses esforços. Na maioria dos países, apesar do grande trabalho do Instituto de Estatística da UNESCO, os dados sobre alfabetização não são confiáveis e o teste LAMP/ UIS $^{11}$ não tem sido usado de forma generalizada. Entretanto, Botswana e Quênia realizaram seus próprios levantamentos inovadores sobre alfabetização.

A educação básica de adultos (em suas múltiplas modalidades e denominações: alfabetização funcional, educação não-formal, segunda chance de escolarização, escola alternativa, equivalência à educação primária) é provavelmente a forma mais comum de educação de adultos na África. Os temas mais discutidos atualmente são: como a dita educação não-formal pode ganhar equivalência (em certificação, status etc.) à escolarização convencional; como seu currículo pode tornar-se efetivamente útil para adultos e, ao mesmo tempo, acelerado em termos de anos de estudo; e se seria melhor ter programas separados para jovens que estão fora da escola e para adultos propriamente ditos.

Assim como acontece com a alfabetização inicial, também no que diz respeito à educação básica de adultos, diversos países estão enfrentando resultados desapontadores e têm necessidade de renovar integramente os sistemas, currículos, materiais e quadros de pessoal. Pouco apoio tem sido dado à criação de ambientes letrados ou à capitalização das línguas maternas como meios efetivos de comunicação e aprendizagem. Raros países têm financiado, de forma

${ }^{11}$ N.T.: UIS é a sigla em inglês do Instituto de Estatística da UNESCO (Unesco Institute for Statistics); LAMP (acrônimo para Literacy Assessment and Monitoring Programme) é um programa elaborado pelo UIS para facilitar o levantamento de dados sobre alfabetização. efetiva, o fornecimento de material de leitura e escrita e de outros recursos educacionais (incluindo a linguagem Braille e de sinais), que são fatores essenciais para garantir o processo de alfabetização, de domínio das operações básicas da matemática e da cultura de aprendizagem ao longo da vida.

Têm sido exaustivamente enfatizados os benefícios da articulação entre a educação básica e o desenvolvimento de habilidades para a vida, o fortalecimento comunitário e as atividades de geração de renda. Há diversos programas que tentam esse caminho. Geralmente - embora com excelentes exceções - tais programas são pouco documentados em termos de estatísticas, monitoramento, avaliações e pesquisas comparativas. Assim, é difícil julgar se essas iniciativas estão sendo abrangentes no atendimento de jovens e adultos.

Evidentemente, a África tem outras formas de educação de adultos além da alfabetização e da educação básica: acesso à educação superior, educação continuada e desenvolvimento profissional, educação técnica, vocacional e para o empreendedorismo, além de uma vasta gama de aprendizagem não-formal, processada por meio de atividades de desenvolvimento e na educação religiosa, cultural, cívica e política. Essas formas de educação tendem a ser mais bem descritas nos relatórios de países africanos mais desenvolvidos, em que, compreensivelmente, elas aparecem de forma mais visível. Entretanto, no geral, dados sobre essas formas de educação são poucos ou inexistentes.

Infelizmente, a África subsaariana está ainda presa a uma armadilha da qual não há escapatória, porque envolve condições mutuamente conflitantes. A região precisa adotar uma ampla abordagem de aprendizagem ao longo da vida, mas tem apenas recursos (e, frequentemente, nem esses) para dedicar atenção à alfabetização e à educação básica. Persistirá ainda a aprendizagem ao longo da vida para o Norte e somente a alfabetização para o Sul?

\section{Inclusões}

Os documentos do Norte estão repletos de referências a "inclusão" - de minorias, de pessoas 
vulneráveis e marginalizadas, dos incapacitados e de outros grupos com necessidades especiais. Em alguma medida, esse discurso da inclusão está começando a aparecer nos relatórios dos países africanos, e a Declaração de Nairóbi conclamou todos os Estados a prover a inclusão em seus programas de aprendizagem e educação de jovens e adultos.

\section{Estruturas nacionais de qualificação}

Pode-se argumentar que as estruturas nacionais de qualificação envolverão a África como um tsunami. Assim, é importante examinar os bons exemplos e identificar, a partir da experiência dos países pioneiros (como África do Sul, Namíbia e Ilhas Seychelles), quais benefícios esses sistemas realmente trazem para os educandos adultos. Talvez seja necessário algum ceticismo ao examinar as exacerbadas promessas de articulação e mobilidade de educandos entre a educação não-formal e a formal. Em que pese a inevitabilidade da criação de estruturas de qualificação nacionais, transnacionais ou internacionais, deve ser tomado muito cuidado para evitar modelos complicados e burocratizados. Devem existir garantias de que tais modelos assegurarão acesso e reconhecimento de aprendizagem anterior (formal e não-formal) de adultos.

\section{Garantia de qualidade: monitoramento e avaliação}

A avaliação de aprendizagem está obviamente acontecendo, mas a qualidade dessa avaliação e os princípios sobre os quais está baseada não estão bem documentados. Em um ambiente que exige cada vez mais o uso de formas transparentes - e internacionalmente comparáveis - de avaliação de competência, tornam-se urgentes o desenvolvimento e a melhor qualidade da avaliação.

Sabe-se que as atividades de monitoramento e avaliação são de importância vital. Ambas necessitam de recursos e da construção de competências, além de maior exposição pública e transparência. Existe uma infinidade de relatórios de avaliação - que nunca foram divulgados de forma adequada - para serem usados por planejadores, pesquisadores e educadores. $\mathrm{Na}$ reunião de Nairóbi, foi recomendado que os processos de garantia de qualidade, monitoramento e a avaliação sejam conduzidos em nível sub-regional e regional. Deve ser desenvolvida também uma estratégia de avaliação por pares, que envolva a sociedade civil. Da mesma forma, devem ser criados sistemas de gestão, comunicação e de informação para produzir e disseminar resultados e as melhores práticas.

\section{O quadro de pessoal e seu desenvolvimento profissional}

Uma das mais perturbadoras revelações do relatório da África diz respeito à existência de uma crise na base do campo da ALE, no nível dos facilitadores da alfabetização, e outra (menos óbvia, mas de particular importância no longo prazo) no topo, junto às instituições de educação superior, que devem apoiar os novos líderes, especialistas e profissionais da educação de adultos.

A maioria dos países relata treinamento inadequado, baixa remuneração e status desvalorizado dos educadores que estão em contato direto com os educandos adultos. Aponta ainda a falta de respeito e de perspectiva de carreira para aqueles profissionais que realmente têm nível mais elevado de qualificação. É possível que a maioria dos educadores de adultos na África seja de fato docente de escola primária ou assistente de professor, com pouca formação específica na educação de adultos.

A profissionalização não é necessariamente um processo fácil; alguns especialistas teriam argumentos contra essa exigência para a educação de adultos; entretanto, a maior parte deles desejaria elevar os padrões, garantir qualificação reconhecida (as novas estruturas nacionais de qualificação apoiariam esse aspecto) e constatar a renovação da política, da pesquisa e da prática, além de maior suporte às instituições de formação.

Os relatórios nacionais são quase omissos em relação ao papel das universidades no apoio à área. No 
entanto, há evidência de que a capacidade de assistência à educação de adultos, por parte das universidades, diminuiu consideravelmente nos últimos doze anos (como, por exemplo, na África do Sul). Essa situação é exacerbada por políticas econômicas e gerenciais que, cada vez mais, afetam as universidades. Países anglófonos ainda têm maior capacidade do que aqueles francófonos, nos quais o desenvolvimento da educação superior é uma urgência.

A Conferência Preparatória, realizada em Nairóbi, recomendou que fosse dada grande atenção às condições de trabalho dos profissionais da educação de jovens e adultos. A qualificação profissional para esses educadores deve ter status comparável àquele dos educadores convencionais. Deve ser incrementada a construção de competências nas áreas de treinamento e pesquisa, por meio da criação e desenvolvimento de institutos de educação superior e de outros tipos de educação de $3^{\circ}$ grau (incluindo as modalidades técnicas e vocacionais), centros de pesquisa e departamentos para a formação de educadores e instrutores. A criação de oportunidades de aprendizagem abertas ou a distância e o uso de tecnologias de informação e comunicação (TIC) devem ser encorajados para apoio e treinamento de educadores e de especialistas em desenvolvimento de materiais.

\section{Informação, pesquisa e o papel de instituições de educação superior}

A atividade de pesquisa, tão vital para a compreensão e a renovação da área, está em declínio nos países africanos. É evidente que há poucas pesquisas e mesmo essas (embora possam ter algum impacto local) não estão sendo divulgadas de forma ampla e efetiva. Há um deserto de dados na África, o que afeta de forma negativa o planejamento e a elaboração de políticas. Assim, será necessário desenvolver melhor competência em pesquisa, incluindo iniciativas sérias de informatização e divulgação de resultados. Isso requer investimento substancial em pesquisa, avaliação e documentação. Sistemas abrangentes de dados devem ser desenvolvidos como parte de sólidos mecanismos de produção e de divulgação de pesquisas. A melhoria dos sistemas de dados depende da definição e padronização, em nível pan-africano, de terminologia e de conceitos relativos à alfabetização, à educação básica de adultos, à educação não-formal e à aprendizagem ao longo da vida. Sem isso, não será possível construir comparações inteligíveis entre regiões ou entre países. Os Estados-membros terão que ser incentivados a desenvolver sua própria capacidade de fornecer tais informações.

Em geral, há notícias pessimistas sobre o papel da educação superior como base de apoio para a educação de adultos, especialmente quanto à pesquisa e à formação de educadores. Muitos países relataram enfraquecimento de tal capacidade (inclusive, catastroficamente, a África do Sul). Em parte, tal retrocesso é consequência da onda de gerencialismo que atingiu as universidades. Muitos dos objetivos colocados para a renovação da educação de adultos, no contexto pós-CONFINTEA VI, requerem que a universidade esteja novamente engajada e fortalecida como parceiro crucial para a produção de pesquisa e para a formação de profissionais para a aprendizagem e educação de adultos. A atual fragilização dessa base deve ser revertida. Há necessidade geral de mais pesquisa, mais levantamentos, mais monitoramento e avaliação, mais estudos de impacto, bem como de divulgação e do uso mais efetivo das pesquisas já realizadas.

Tanto em nível nacional quanto no regional, é preciso que relatórios, pesquisas, avaliações e outros documentos referentes à educação e à aprendizagem de adultos estejam digitalizados e disponíveis na internet. Deve haver um forte compromisso de compartilhar documentação e materiais. Cada país deve ter uma base de dados sistemática e abrangente sobre a provisão e a prática da aprendizagem e educação de adultos.

\section{Recomendações para a CONFINTEA VI}

A recomendação geral dos Estados-membros africanos quanto às resoluções da CONFINTEA VI diz respeito principalmente à necessidade de um compromisso verdadeiro e de adequado acompanhamento/ 
monitoramento dos desdobramentos da conferência (com o apoio necessário para esse processo). Há uma percepção generalizada de que foi falho o acompanhamento das propostas da CONFINTEA anterior. Várias sugestões foram feitas quanto a mecanismos de monitoramento. Por exemplo: para implementar as recomendações da CONFINTEA VI, os países africanos deveriam estabelecer processos de acompanhamento com referências e indicadores bem definidos. Os resultados de tais atividades deveriam ser comunicados e compartilhados em nível regional.

Há, sobretudo, grande expectativa de que a CONFINTEA VI se realize com uma orientação voltada para ação e para resultados. Foi recomendada a constituição de um grupo de defesa da aprendizagem e educação de adultos, formado por membros dos governos, organizações bi e multilaterais, pelo setor privado e pela sociedade civil em geral. Seu objetivo seria levantar fundos para a aprendizagem e educação de adultos, considerando seriamente as necessidades da África subsaariana. Foi destacado que a cooperação nas políticas - e em outras áreas da aprendizagem e educação de adultos - teria mais substância se fossem criadas mais redes e fosse estabelecido maior intercâmbio Sul-Sul, Sul-Norte e entre francófonos, anglófonos e lusófonos. Os governos participantes devem assumir um forte compromisso para revitalizar a aprendizagem e a educação de adultos. Deve ser elaborada uma agenda para um rápido e efetivo acompanhamento das ações em nível internacional, regional e nacional.

As expectativas são altas. Em dezembro de 2009, haverá confirmação se tais expectativas serão satisfeitas.

JOHN AITCHISON, professor titular de educação de adultos na Universidade KwaZulu de Natal, na África do Sul. Aposentado em 2007, é atualmente consultor independente nesse país. Em parceria com Hassana Alidou, foi encarregado de compilar o relatório $O$ desenvolvimento e o estado da arte da educação e da aprendizagem de adultos na África subsaariana para a CONFINTEA VI. Últimas publicações: AITCHISON, John J. W.; HARLEY, Anne. South African illiteracy statistics and the case of the magically growing number of literacy and ABET learners (Journal of Education, n. 39, p. 89-112, 2006); Brak! - vision, mirage and reality in the post apartheid globalisation of South African adult education and training (In: HAKE, Barry; VAN GENT, Bastian; KATUS, Josef (Eds.). Adult education and globalisation: past and present. Frankfurt am Main: Peter Lang, 2004. p. 251-268). E-mail: aitchisonjjw@gmail.com, aitchisonj@ukzn.ac.za

Recebido em março de 2009 Aprovado em abril de 2009 
freireano de educación, visando contribuir para la construcción de la ciudadanía y la participación. El desafío para la CONFINTEA VI es construir síntesis capaces de llevar a consensos sobre contenidos y métodos de educación de jóvenes y adultos, además de atender a las urgencias, mirando la educación no como costo o inversión, sino como derecho y servicio, y promover la construcción de espacios públicos en los que se erija la totalidad social con la especificidad de cada grupos, en el contexto del multiculturalismo.

Palabras claves: educación de jóvenes y adultos; nuevos paradigmas; multiculturalismo.

John Aitchison

\section{A voz do Sul na CONFINTEA VI: a} agenda da África

O texto é uma síntese da agenda africana para a CONFINTEA VI, preparada a partir de relatórios nacionais trazidos pelos 46 países africanos reunidos em Nairóbi, Quênia, em novembro de 2008. Depois de breve descrição de um contexto desencorajador, o autor elenca as questões que foram consideradas prioritárias quanto à estrutura, gestão, financiamento e qualidade da educação de adultos na África. Diante da constatação de que os problemas da área são massivos, abrangentes e sistêmicos, os representantes reunidos em Nairóbi sugeriram maior intercâmbio entre países e a formação de um grupo de alto nível, multissetorial, que levantasse fundos para o financiamento da educação de adultos na África. Além disso, recomendaram que a CONFIN-

TEA VI tivesse uma orientação voltada para resultados e para ação e que fosse estabelecido um sistema efetivo de acompanhamento da implementação das deliberações tomadas.

Palavras-chave: educação de adultos na África; CONFINTEA VI.
The South speaking to CONFINTEA VI: the African agenda

The text is a synthesis of the African agenda for CONFINTEA VI based on national reports prepared by 46 African countries present in Nairobi, Kenya, in November 2008. After a brief description of the discouraging context, the author lists the questions which were considered priority with regard to structure, management, financing and quality of adult education in Africa. Faced with the affirmation that the problems of the area are massive, wide-ranging and systemic, the representatives present in Nairobi suggested greater exchange between countries and the creation of a multi-sectoral high level group to raise funds for the financing of adult learning and education in Africa. In addition, they recommended that CONFINTEA VI should be oriented towards results and action and that an effective system for monitoring the implementation of the deliberations taken should be established.

Key words: adult education in Africa; CONFINTEA VI.

\section{La voz del Sur en la CONFINTEA} VI: la agenda de África

El texto es una síntesis de la agenda africana para la CONFINTEA VI, preparada a partir de informes nacionales traídos por los 46 países africanos reunidos en Nairobi, Kenia, en noviembre de 2008. Después de de una breve descripción de un contexto desencorajador, el autor numera las cuestiones que fueron consideradas prioritarias en cuanto a la estructura, gestión, financiamiento y calidad de la educación de adultos en África. Delante de la constatación de que los problemas del área son masivos, abrangentes y sistémicos, los representantes reunidos en Nairobi sugirieron un mayor intercambio entre países y la formación de un grupo de alto nivel, multisectorial, que levantara fondos para el financiamiento de la educación de adultos en África. Además de esto, recomendaron que la CONFINTEA VI tuviera una orientación apuntada para resultados y para acción, y que fuera establecido un sistema efectivo de acompañamiento de la implementación de las deliberaciones tomadas.

Palabras claves: educación de adultos en África; CONFINTEA VI.

Heribert Hinzen

Educação de adultos

ao longo da vida: desenvolvimentos atuais e interdependentes na Alemanha e na Europa, a caminho da VI CONFINTEA

A educação e a aprendizagem de adultos têm recebido mais atenção e reconhecimento a partir do conceito de aprendizagem ao longo da vida, que se torna agora o principal paradigma para a teoria e a prática educacionais. Este movimento se acentua no contexto de organismos como a UNESCO, a União Europeia e a Associação Alemã de Educação de Adultos (DVV), no caso da Alemanha. Há claras indicações de que cada um desses organismos exerce mútua influência sobre os outros, por meio das políticas, programas, modelos e até mesmo pela administração de recursos financeiros. Isto é exemplificado no artigo pela indicação de processos que vêm ganhando importância nos últimos anos, na preparação da VI Conferência Mundial de Educação de Adultos - VI CONFINTEA.

Palavras-chave: educação de adultos na Europa; VI CONFINTEA.

Lifelong Adult

education: current and

interdependent developments in

Germany, Europe and elsewhere, on the road to CONFINTEA VI

Adult learning and education

has received more attention and recognition since the dissemination of the concept of lifelong learning, which 